\title{
Angiotensin-I Converting Enzyme Inhibitor Activity in Japanese Burdock Roots
}

\author{
Shougo Kawamura ${ }^{1}$, Takayuki Murakami ${ }^{2}$, Kohji Ishihara ${ }^{1} \&$ Noriyoshi Masuoka ${ }^{1}$ \\ ${ }^{1}$ Department of Life Science, Okayama University of Science, Kita-ku, Okayama, Japan \\ ${ }^{2}$ Ahjikan Co. Ltd., Nishi-ku, Hiroshima, Japan \\ Correspondence: Noriyoshi Masuoka, Department of Life Science, Okayama University of Science, 1-1 \\ Ridai-cho, Kita-ku, Okayama 700-0005, Japan. Tel: 81-86-256-9593. E-mail: masuokan@dls.ous.ac.jp
}

Received: October 17, 2014 Accepted: December 17, 2014 Online Published: December 23, 2014

doi:10.5539/jfr.v4n2p51

URL: http://dx.doi.org/10.5539/jfr.v4n2p51

\begin{abstract}
Japanese burdock roots were extracted with aqueous methanol solution. A compound having the inhibitory activity of angiotensin I-converting enzyme (ACE)[EC 3.4.15.1] was purified and identified as nicotianamine, (2S, 3'S, 3"S)- $N$-[N-(3-amino-3-carboxypropyl)-3-amino-3-carboxypropyl]azetidine-2-carboxylic acid. The compound content in burdock roots and related food products were determined. Data revealed that burdock root is a good source of nicotianamine (NA).
\end{abstract}

Keywords: nicotianamine, angiotensin-1 converting enzyme inhibitor, Japanese burdock

\section{Introduction}

The root of the Japanese burdock plant, Artium lappa, is edible in Korea and Japan. The root contains a high amount of dietary fibers $(5.7 \%)$, with low amounts of fat $(0.1 \%)$ and protein $(1.8 \%)$ with the rest comprised of water (81.7\%) (Ministry of Education, Culture, Sports, Science and Technology, Japan, 2005), and is a low calorie food. The root also contains a considerable amount of polyphenols such as chlorogenic, caffeoylquinic and hydroxycinnamoylquinic acids and related compounds (Maruta, Kawabata, \& Niki, 1995; Lin \& Harnly, 2008). The ingestion of the root products results in anti-inflammatory activity, an elevation of cecum Bifidobacterium and a preventative effect against oxidative stress (Sohn et al., 2011; Okazaki et al., 2013; Takemoto et al., 2014). It was also reported that burdock root extract inhibits angiotensin I-converting enzyme (ACE). The ACE is a key enzyme in the angiotensin-renin system that controls blood pressure, since ACE catalyzes the conversion from angiotensin I to the active angiotensin, which raises the blood pressure by acting on the adrenal cortex. Therefore, burdock root was extracted with aqueous media and fractionated with organic solvents to pursue the bioactive compounds. A compound having the inhibitory activity was isolated and assigned as nicotianamine (NA), (2S, 3'S, 3' $S$ )- $N$-[ $N$-(3-amino-3-carboxypropyl)-3-amino-3carboxypropyl]azetidine-2-arboxylic acid (Kristensen \& Larsen, 1974). The content level in burdock root and the food products was estimated.

\section{Materials and Methods}

\subsection{Materials}

Amberlite IR-120B was obtained from Organo Co. (Tokyo, Japan). Hippuryl- L-histdiyl-L-leucine, ACE (rabbit lung), Dowex 1X4 and Dowex 50WX8 were obtained from Sigma-Aldrich Chemical Co. (MO, USA). A Sephadex LH-20 was obtained from GE Healthcare UK. Ltd., (England). A TLC plate (silica gel $60 \mathrm{~F}_{254}$ ) was obtained from Merck Co. (Germany). Other chemicals used for the experiments were reagent grade and purchased from Wako Pure Chemical Ind. Ltd. (Osaka, Japan).

Burdock roots (harvested in Okayama Prefecture) were purchased from a local store in Okayama. The burdock root food products were prepared by Ahjikan Co Ltd (Hiroshima, Japan) as follows. Burdock roots were cut into small pieces and then dried using air drying oven at $50{ }^{\circ} \mathrm{C}$ for $4 \mathrm{hrs}$ (dry product). The dried pieces were roasted at approximately $200{ }^{\circ} \mathrm{C}$ for $10 \mathrm{~min}$ (roasted product). These pieces were fried in vegetable oil at $135^{\circ} \mathrm{C}$ for 7 min (fried product). The dried pieces were mixed with an equal amount of water and $0.1 \%$ Aspergillus awamori spores (final concentration, w/w) and the mixture was fermented at $35^{\circ} \mathrm{C}$ for $40 \mathrm{hrs}$ (fermented product) (Okazaki et al., 2013; Takemoto et al., 2014). Amino acids were analyzed using a Hitachi L-8800 analyzer 
(Hitachi Co. Ltd., Tokyo, Japan) fitted with $0.46 \times 6.0 \mathrm{~cm}$ column packed with Hitachi custom ion-exchange resin (No. 2622PF) and equipped with post-column detection by ninhydrin. Electrospray ionization mass spectra (ESI-MS) were measured using LC-MS (Accu TOF CS, JEOL Ltd., Tokyo, Japan equipped with HPLC).

\subsection{The ACE Inhibition Assay}

The inhibitory activity was assayed by a reported method with a slight modification (Cushman \& Cheung, 1971). The sample was dissolved in water. A sample solution of $50 \mu \mathrm{L}$ was added to $150 \mu \mathrm{L}$ of $7.0 \mathrm{mM}$ hippuryl-L-histdiyl-L-leucine in $0.125 \mathrm{M}$ borate buffer $(\mathrm{pH} 8.3)$. The mixture was preincubated at $37^{\circ} \mathrm{C}$ for 5 $\min$. To the mixture, $50 \mu \mathrm{L}$ of ACE solution $(100 \mathrm{mU} / \mathrm{mL})$ was added and reacted for $10 \mathrm{~min}$. The reaction was stopped by adding $1 \mathrm{M}$ hydrochloric acid at $250 \mu \mathrm{L}$. The mixture $(10 \mu \mathrm{L})$ was analyzed by HPLC. A column $(\Phi$ $0.46 \times 15 \mathrm{~cm}$, CrestPak C18S column, Jasco Co. Tokyo, Japan) was used, and the mobile phase was consisted of $5 \%$ acetonitrile and $95 \%$ water containing $0.5 \%$ formic acid. The flow rate was $1.0 \mathrm{~mL} / \mathrm{min}$. The detection was absorbance at $228 \mathrm{~nm}$.

\subsection{Extraction of ACE Inhibitor From Japanese Burdock Root}

Burdock root $(10.0 \mathrm{~g})$ was homogenized three-times with 5 volumes of $50 \%$ methanol in water. The extracts were collected and evaporated using a rotary evaporator. The residue was dissolved with $50 \mathrm{~mL}$ of water (Fraction 1). The fraction 1 was extracted three-times with $50 \mathrm{~mL}$ of ethyl acetate. The ethyl acetate layers were collected and evaporated (Fraction 2). The aqueous layer (Fraction 3) was extracted three-times with $50 \mathrm{~mL}$ of $n$-butanol. The $n$-butanol extracts were collected and evaporated (Fraction 4). The aqueous layer was Faction 5. Each fraction was dissolved with water so as to make up $50 \mathrm{~mL}$ and the inhibitory activity was analyzed (Figure $1)$.

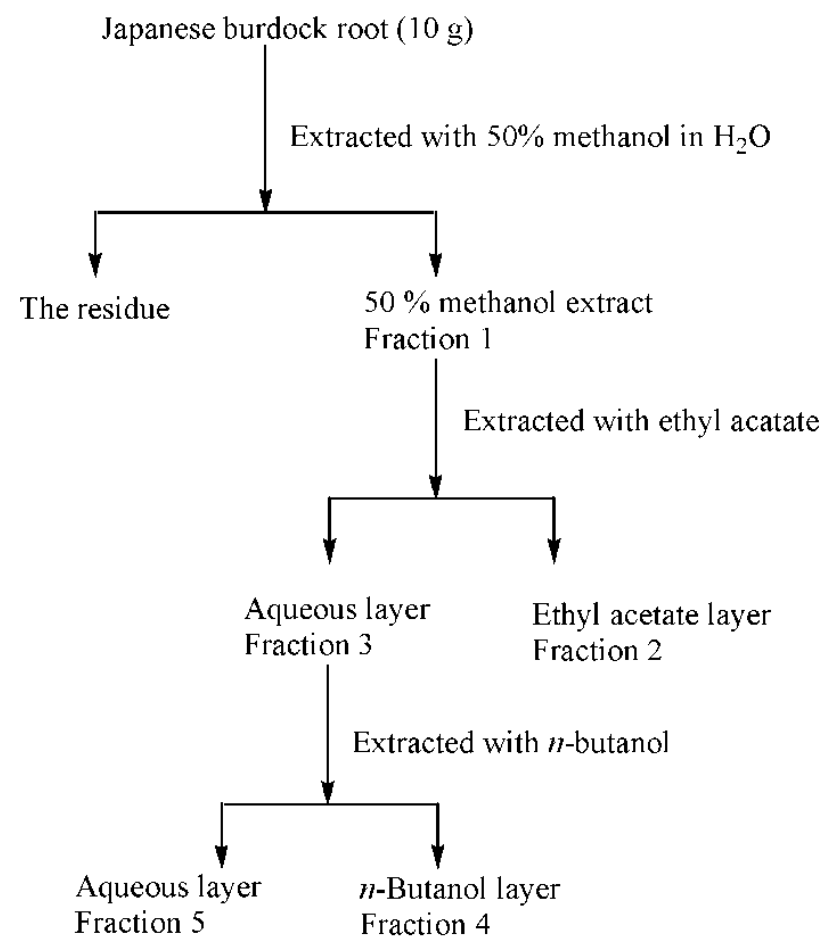

Figure 1. Extraction from Japanese burdock root and separation with organic solvents

\subsection{Isolation of the ACE inhibitor From Burdock Root}

Burdock root $(10.0 \mathrm{~g})$ was powdered with a mixer for $1 \mathrm{~min}$. The mixture was extracted three-times with hot water $\left(100{ }^{\circ} \mathrm{C}, 50 \mathrm{~mL}\right)$ for $10 \mathrm{~min}$, and the extract was washed with $n$-butanol. The water layer was applied to a cation-exchange column (Amberlite IR-120B, $\mathrm{H}^{+}$-form, $\Phi 4.0 \times 24 \mathrm{~cm}$ ). The column was eluted with water (900 $\mathrm{mL}$ ) and then $2.0 \mathrm{M}$ ammonia $(900 \mathrm{~mL})$. The ammonia fraction was collected and evaporated, and the residue was applied to a cation-exchange column (Dowex 50WX8, $\mathrm{H}^{+}$-form, $\Phi 2.0 \times 12 \mathrm{~cm}$ ). The column was eluted with water $(120 \mathrm{~mL}), 2 \mathrm{M} \mathrm{HCl}(120 \mathrm{~mL})$ and then $2.0 \mathrm{M}$ ammonia $(120 \mathrm{~mL})$. The ammonia fraction $(50-100$ $\mathrm{mL}$ ) was collected and evaporated, and the residue was applied to an anion-exchange column (Dowex 1X4, 
acetate-form, $\Phi 2.0 \times 12 \mathrm{~cm})$. The column was eluted with water $(120 \mathrm{~mL})$ and $0.2 \mathrm{M}$ acetic acid $(120 \mathrm{~mL})$. The fraction between $50 \mathrm{~mL}$ and $100 \mathrm{~mL}$ of $0.2 \mathrm{M}$ acetic acid was collected and applied to a gel filtration column (Sephadex LH-20, $\Phi 2.0 \times 12 \mathrm{~cm}$ ). The column was eluted with water and the fraction between $50 \mathrm{~mL}$ and 100 $\mathrm{mL}$ was collected. The fraction was further purified with TLC (silica gel, $0.2 \times 8.0 \times 4.0 \mathrm{~cm}$, ammonia: $n$-propanol =1: 1). The region with an $\mathrm{R}_{\mathrm{f}}$ value between 0.67 and 0.69 was scraped, and the gel powders were gathered and extracted in distilled water. Finally, $0.12 \mathrm{mg}$ of an inhibitor $(0.0012 \%)$ was isolated.

\subsection{Determination of the NA Content in Burdock and the Related Food Products}

Each sample from burdock root $(1.0 \mathrm{~g})$ was immediately homogenized and extracted twice with $5.0 \mathrm{~mL}$ of hot water $\left(100^{\circ} \mathrm{C}\right)$ for $10 \mathrm{~min}$. The extract $(1 \mathrm{vol}$.) was dissolved with 24 volumes of $0.02 \mathrm{M} \mathrm{HCl}$. The solution $(20$ $\mu \mathrm{L}$ ) was analyzed with the L-8800 analyzer. The column was eluted with lithium citrate buffers according to manufacturer's instructions for biological fluid. The flow rate was $0.35 \mathrm{~mL} / \mathrm{min}$.

\section{Results}

\subsection{Inhibitory Activity of ACE in Each Extraction Fraction From Burdock Root}

Inhibitory activity in each burdock root fraction (from $10.0 \mathrm{~g}$ ) was indicated in Table 1.

Table 1. The ACE-Inhibitory activity in each burdock root fractions shown in Figure 1

\begin{tabular}{lllll}
\hline Fraction & Weight $(\mathrm{g})$ & Inhibitory activity $(\%)$ & $\mathrm{IC}_{50}(\mathrm{~g} / \mathrm{L})$ & Purification \\
\hline 1 & 3.763 & $37.2 \pm 0.8$ & 10.1 & 1.00 \\
2 & 0.114 & $0.0 \pm 0.0$ & - & - \\
3 & 3.702 & $34.7 \pm 4.3$ & 10.7 & 0.94 \\
4 & 0.770 & $0.0 \pm 0.0$ & - & - \\
5 & 3.066 & $21.1 \pm 3.9$ & 14.8 & 0.70 \\
\hline
\end{tabular}

The result indicates that the ACE inhibitory activity is present in the aqueous fractions. When the aqueous layer of the root extract was washed with organic solvents, the inhibitory activity in the aqueous layer was reduced. This suggests that the decrease of the activity is in part attributable to the lability of NA.

\subsection{Identification of the Inhibitor Isolated From Burdock Root}

Negative ESI-MS data indicated: $\mathrm{m} / \mathrm{z} 302\left(100 \%, \mathrm{M}-\mathrm{H}^{+}\right), 284\left(\mathrm{M}-\mathrm{H}^{+}-18\right)$. The high resolution mass spectrum (ESI-HRMS) of the base peak was found to be 302.13559 (the calculated value was 302.13521 as $\mathrm{C}_{12} \mathrm{H}_{20} \mathrm{~N}_{3} \mathrm{O}_{6}$ ). The NMR data (data not shown) are consistent with those of nicotianamine (Kristensen \& Larsen, 1974; Budesinsky et al., 1981; Kuroda, Ishihara \& Masuoka, 2013). HPLC analysis of the inhibitor from burdock was carried out under the following condition: A column $(\Phi 0.3 \times 15 \mathrm{~cm}$, CrestPak C18S column, Jasco Co.) was used. The flow rate was $0.3 \mathrm{~mL} / \mathrm{min}$. The injection volume was $10.0 \mu \mathrm{L}$. The wavelength was $200 \mathrm{~nm}$. Analysis was carried out with a linear gradient of water from $5 \%$ to $100 \%$ acetonitrile for $15 \mathrm{~min}$. The retention time (RT) of the inhibitor was $6.27 \mathrm{~min}$. Analysis with an amino acid analyzer indicated that the RT of the inhibitor was $43.2 \mathrm{~min}$. (Val was eluted at $42.5 \mathrm{~min}$, and Cys at $44.8 \mathrm{~min}$ ). The RTs of HPLC and the amino acid analyzer were the same for NA as we previously reported. From these data, we assigned the inhibitor as NA (Figure 2).

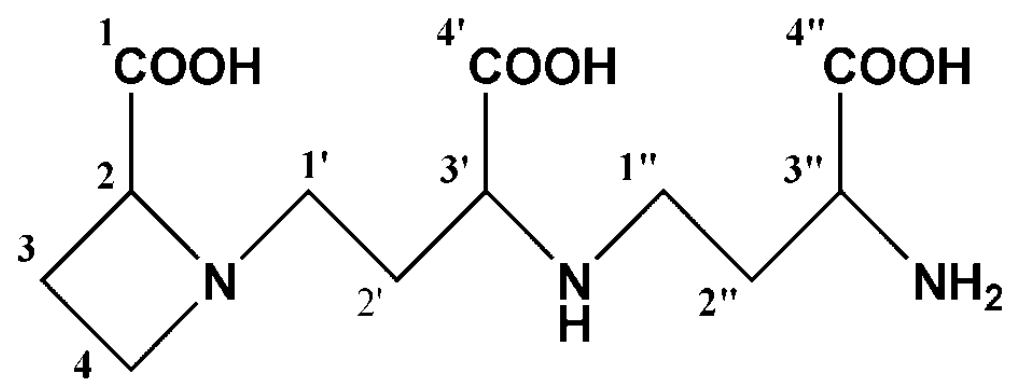

Figure 2. Nicotianamine : (2S, 3'S, 3"S)- $N$-[N-(3-amino-3-carboxypropyl)-3-amino-3-carboxypropyl]azetidine-2-carboxylic acid 


\subsection{Inhibition of ACE Activity and NA Content in Burdock Products}

As there are burdock root food products, the NA content in these products was examined. The NA content was determined using an amino acid analyzer (RT $43.2 \mathrm{~min}$ ). The inhibitory activity and NA content in the burdock products are indicated in Table 2. The content was the highest in dry burdock root and was found to decrease by roasting, frying or fermentation.

Table $2 . \mathrm{IC}_{50}$ of ACE activity and nicotianamine content in burdock and related products

\begin{tabular}{lll}
\hline Burdock root & $\mathrm{IC}_{50}$ of ACE activity $(\mathrm{g} / \mathrm{L})$ & Nicotianamine $(\mu \mathrm{g} / \mathrm{g}$ of dry weight $)$ \\
\hline Raw & $7.40 \pm 0.01$ & $312 \pm 19$ \\
Dry & $1.27 \pm 0.05$ & $511 \pm 26$ \\
Roasted & $15.30 \pm 0.92$ & $111 \pm 8$ \\
Fried & $\mathrm{ND}^{*}$ & $145 \pm 12$ \\
Fermented & $12.90 \pm 2.69$ & $230 \pm 10$ \\
\hline
\end{tabular}

* ND indicates "not determined".

The relation between the $\mathrm{IC}_{50} \mathrm{~S}$ and NA content in the burdock products was analyzed. The data indicate a reverse interrelation $\left(\mathrm{R}^{2}=0.919\right)$. This suggests the ACE inhibition in these food products is mainly due to NA.

\section{Discussion}

Japanese burdock root was extracted with aqueous methanol solution and inhibitory ACE activity of the extracts was examined. The inhibitory activity was only detected in the aqueous fraction. Therefore, burdock root was extracted with hot water and the extract was purified using column chromatography. The structure of the inhibitor was identified as NA from the NMR and MS spectra as well as chromatographic behaviour. Since the inhibitory activity and NA content in burdock products exhibited a reverse interrelation (Table2) and the Lineweaver-Burk plot data of the inhibitory activity in Fraction 1 (data not shown) are quite similar with purified NA (Figure 3), the inhibitory activity in Japanese burdock root was mostly due to NA. Purified NA exhibited an inhibition that was a mixed type, which is the same as in the Hayashi \& Kimoto report (Hayashi \& Kimoto, 2007), i.e. both competitive and non-competitive inhibition, with the kinetic parameters determined as $\mathrm{Ki}=0.40$ and $\mathrm{Ki}=1.56 \mu \mathrm{M}$. These kinetic parameters suggest that NA competitively bound to the active site by chelating $\mathrm{Zn}$ in $\mathrm{ACE}$. The $\mathrm{IC}_{50}$ of NA was found to be $481 \mathrm{nM}$, which is similar to the values reported (Kinoshita, Yamakoshi, \& Kikuchi, 1993; Takenaka, Murayama, Furusho, \& Takenaka, 2009). Although the inhibition activity of NA was considerably less than captopril $\left(\mathrm{IC}_{50}=22 \mathrm{nM}\right)$ (Fujita \& Yoshikawa, 1999), the ingestion of NA from soybean broth was able to ameliorate high blood pressure in spontaneously hypertensive rats (Takenaka et al., 2009). Therefore, the NA content in burdock root products was estimated (Table 2). In raw burdock root, the NA content was found to be higher than Jew's mallow (Corchorus olitorius) (Kimoto et al., 1998), and hayatouri (Sechium edule) (Hayashi, Nakayama, Aoyagi, \& Kimoto, 2005), but it was slightly lower than in raw soybeans (Kuroda et al., 2013). The NA content in the dried burdock root is the highest among the burdock products. When the content in fermented burdock root (powders) was compared to that of a soy source, fermented soybeans (Kinoshita et al., 1993; Kataoka, 2005; Kuroda et al., 2013), it was obvious that the NA content in fermented burdock is considerable higher. Though the NA content in the root is decreased by roasting, the content in roasted burdock root is also considerably high. These results suggest that Japanese burdock root is a good source of NA. As the roasted root is extracted with hot water and the beverage is served as the tea "Gobou cha" in Japan, drinking of this beverage may help lower hypertension. Further study is currently underway. 


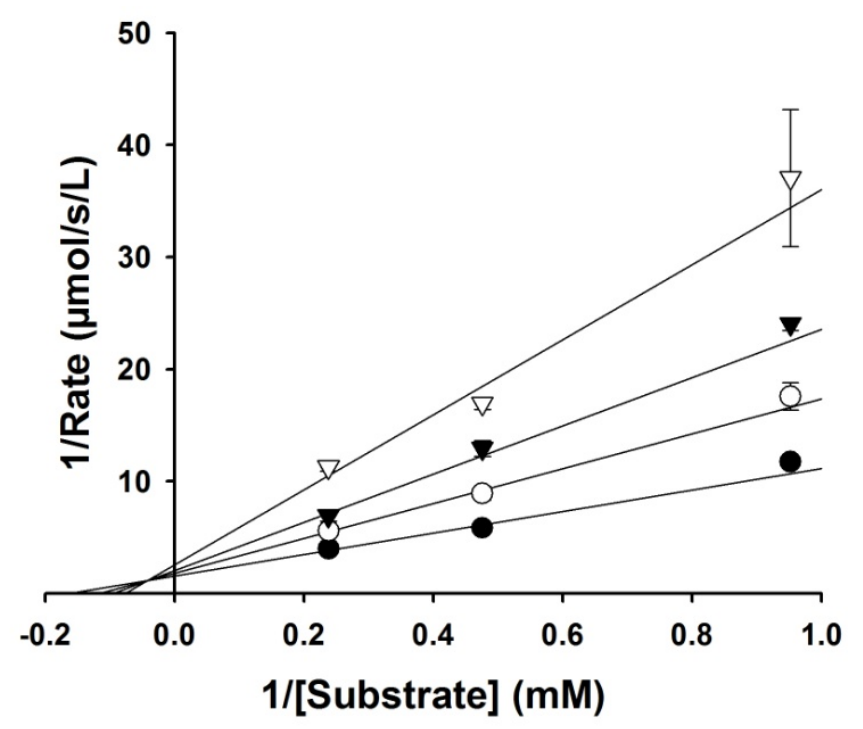

Figure 3. Lineweaver-Burk plot of ACE inhibition with NA. Closed circle indicates $0 \mu \mathrm{M}$ NA; open circle, $0.25 \mu \mathrm{M}$; closed triangle, $0.50 \mu \mathrm{M}$; open triangle, $1.0 \mu \mathrm{M}$

\section{Conclusion}

A compound having ACE inhibitory activity from Japanese burdock root was purified and identified as NA. The compound content in burdock root and related food products were determined. Burdock root is a good source of NA.

\section{References}

Budesinsky, M., Prochazka, Z., Budzikiewicz, H., Romer, A., Ripperger, H., Schreiber, K., \& Scholz, G. (1981). On the "normalizing factor" for the tomato mutant "chloronerva"-XI. Tetrahedron, 37, 191-196. http://dx.doi.org/10.1016/S0040-4020(01)97734-8

Cushman, D. W., \& Cheung, H. S. (1971). Spectrophotometric assay and properties of the angiotensin-converting enzyme of rabbit lung. Biochem. Pharmacol., 20, 1637-1648. http://dx.doi.org/10.1016/0006-2952(71)90292-9

Fujita, H., \& Yoshikawa, M. (1999). LKPNM: a prodrug-type ACE-inhibitory peptide derived from fish protein. Immunopharmacology, 44, 123-127. http://dx.doi.org/10.1016/S0162-3109(99)00118-6

Hayashi, A., Nakayama, T., Aoyagi, Y., \& Kimoto, K. (2005). Purification of Nicotianamine from Hayatouri (Sechium Edule) and Estimation of Quantitative Determination Method. Nippon Shokuhin Kagaku Kogaku Kaishi, 52(4), 154-159. http://dx.doi.org/10.3136/nskkk.52.154

Hayashi, A., \& Kimoto, K. (2007). Nicotianamine Preferentially Inhibits Angiotensin I -Converting Enzyme. Journal of Nutritional Science and Vitaminology, 53(4), 331-336. http://dx.doi.org/10.3177/jnsv.53.331

Kataoka, S. (2005). Functional effects of Japanese style fermented soy sauce (shoyu) and its components. Journal of Bioscience and Bioengineering, 100(3), 227-234. http://dx.doi.org/10.1263/jbb.100.227

Kimoto, K., Kuroda, Y., Saito, Y., Yamamoto, J., Murakami, T., \& Aoyagi, Y. (1998). Purification and identification of angiotensin I-converting enzyme inhibitory from morokheiya (Corchorus olitorius). Food Sci. Technol. Int. Tokyo, 4(3), 223-226. http://dx.doi.org/10.3136/fsti9596t9798.4.223

Kinoshita, E., Yamakoshi, J., \& Kikuchi, M. (1993). Purification and identification of an angiotensin I-converting enzyme inhibitor from soy sauce. Biosci. Biotech. Biochem., 57(7), 1107-1110. http://dx.doi.org/10.1271/bbb.57.1107

Kristensen, I., \& Larsen, P. O. (1974). Azetidine-2-carboxylic acid derivatives from seeds of fagus silvatica L.and revised structure for nicotianamine. Phytochemistry, 13, 2791-2798. http://dx.doi.org/10.1016/0031-9422(74)80243-8 
Kuroda, K., Ishihara, K., \& Masuoka, N. (2013). Characterization of Nicotianamine Isolated from Soybeans. Journal of Food Research, 2(2), 49-54. http://dx.doi.org/10.5539/jfr.v2n2p49

Lin, L-Z., \& Harnly, J. M. (2008). Identification of hydroxycinnamoylquinic acids of arnica flowers and burdock roots using a standardized LC-DAD-ESI/MS profiling method. J. Agric. Food Chem., 56, 10105-10114. http://dx.doi.org/10.1021/jf802412m

Maruta, Y., Kawabata, J., \& Niki, R. (1995). Antioxidative caffeoylquinic acid derivatives in the roots of burdock (Arctium lappa L.). J. Agric. Food Chem., 43, 2592-2595. http://dx.doi.org/10.1021/jf00058a007

Ministry of Education, Culture, Sports, Science and Technology, Japan (ed.). (2005). Standard table of food composition in Japan, fifth revised and enlarged edition.

Okazaki, Y., Sitanggang, N. V., Sato, S., Ohnishi, N., Inoue, J., Iguchi, T., ... Kato, N. (2013). Burdock fermented by Aspergillus awamori elevates cecum Bifidobacterium, and reduces fecal deoxycholic acid and adipose tissue weight in rats fed a high-fat diet. Biosci. Biotechnol. Biochem., 77, 53-57. http://dx.doi.org/10.1271/bbb.120551

Sohn, E. H., Jang, S. A., Joo, H., Park, S., Kong, S. C., Lee, C. H., \& Kim, S. Y. (2011). Anti-allergic and anti-inflammatory effects of butanol extract from Arctium lappa L. Clin Mol Allergy, 9, 4. http://dx.doi.org/10.1186/1476-7961-9-4

Takemoto, K., Doi, W., Zukeran, A., Inoue, J., Ishihara, K., \& Masuoka, N. (2014). Effect of Aspergillus awamori-fermented burdock root on mouse diabetes induced by alloxan-prevention of cell apoptosis. Food and Nutrition Science, 5, 1554-1560. http://dx.doi.org/10.4236/fns.2014.516168

Takenaka, T., Murayama, T., Furusho, T., \& Takenaka, Y. (2009). Antihypertensive effects of nicotianamine from soybean broth in spontaneously hypertensive rats, Food Sci. Technol. Res, 15(5), 541-546. http://dx.doi.org/10.3136/fstr.15.541

\section{Copyrights}

Copyright for this article is retained by the author(s), with first publication rights granted to the journal.

This is an open-access article distributed under the terms and conditions of the Creative Commons Attribution license (http://creativecommons.org/licenses/by/3.0/). 